University of Wollongong

Research Online

Faculty of Engineering and Information

Faculty of Engineering and Information

Sciences - Papers: Part B

Sciences

2017

\title{
Evaluation of fertilizer-drawn forward osmosis for coal seam gas reverse osmosis brine treatment and sustainable agricultural reuse
}

\author{
Youngjin Kim \\ Korea University, University of Technology Sydney \\ Yun Chul Woo \\ University of Technology Sydney \\ Sherub Phuntsho \\ University of Technology Sydney \\ Long D. Nghiem \\ University of Wollongong, longn@uow.edu.au \\ Ho Kyong Shon \\ University of Technology Sydney, hkshon@enguts.edu.au
}

See next page for additional authors

Follow this and additional works at: https://ro.uow.edu.au/eispapers1

Part of the Engineering Commons, and the Science and Technology Studies Commons 


\title{
Evaluation of fertilizer-drawn forward osmosis for coal seam gas reverse osmosis brine treatment and sustainable agricultural reuse
}

\author{
Abstract \\ The fertilizer-drawn forward osmosis (FDFO) was investigated for treating coal seam gas (CSG) produced \\ water to generate nutrient rich solution for irrigation. Its performance was evaluated and compared with \\ reverse osmosis (RO) in terms of specific energy consumption (SEC) and nutrient concentrations in the \\ final product water. The RO-FDFO hybrid process was developed to further improve FDFO. The results \\ showed that FDFO has the lowest SEC followed by the RO-FDFO and RO processes. The final nutrient \\ concentration simulation demonstrated that the RO-FDFO hybrid process has lower final concentration, \\ higher maximum recovery and lower nutrient loss than the stand alone FDFO process. Therefore, it was \\ suggested that the RO-FDFO is the most effective treatment option for CSG produced water as well as \\ favourable nutrient supply. Lastly, membrane fouling mechanism was examined in CSG RO brine \\ treatment by FDFO, and the strategies for controlling fouling were critically evaluated. KNO3 exhibited the \\ highest flux decline corresponding to the highest reverse salt flux, while the most severe membrane \\ scaling was observed with calcium nitrate, primarily due to the reverse transport of calcium ions. To \\ control membrane fouling in FDFO process, both physical flushing and chemical cleaning were examined. \\ Membrane cleaning with citric acid of $5 \%$ resulted in a complete flux recovery.

\section{Disciplines} \\ Engineering | Science and Technology Studies

\section{Publication Details} \\ Kim, Y., Woo, Y. Chul., Phuntsho, S., Nghiem, L. D., Shon, H. \& Hong, S. (2017). Evaluation of fertilizer-drawn \\ forward osmosis for coal seam gas reverse osmosis brine treatment and sustainable agricultural reuse. \\ Journal of Membrane Science, 537 22-31.
}

\section{Authors}

Youngjin Kim, Yun Chul Woo, Sherub Phuntsho, Long D. Nghiem, Ho Kyong Shon, and Seungkwan Hong 
1 Evaluation of fertilizer-drawn forward osmosis for coal seam gas reverse osmosis

\section{2 brine treatment and sustainable agricultural reuse}

3

4 Youngjin Kim ${ }^{\mathrm{a}, \mathrm{b}}$, Yun Chul Woo ${ }^{\mathrm{b}}$, Sherub Phuntsho ${ }^{\mathrm{b}}$, Long D. Nghiem ${ }^{\mathrm{c}}$, Ho Kyong

$5 \quad$ Shon ${ }^{b^{*}}$, Seungkwan Hong ${ }^{a^{*}}$

6

$7{ }^{\mathrm{a}}$ School of Civil, Environmental and Architectural Engineering, Korea University, 1-5 Ga,

8 Anam-Dong, Seongbuk-Gu, Seoul, 136-713, Republic of Korea

$9{ }^{\mathrm{b}}$ Centre for Technology in Water and Wastewater, School of Civil and Environmental 10 Engineering, University of Technology Sydney (UTS), Post Box 129, Broadway, NSW

112007 , Australia

$12{ }^{c}$ Strategic Water Infrastructure Laboratory, School of Civil Mining and Environmental

13 Engineering, University of Wollongong, Wollongong, NSW 2522, Australia

14

15

16

17

18

19

$20 *$ Co-corresponding authors.

21 Hokyong Shon. Tel.: +61-2-9514-2629; E-mail: Hokyong.Shon-1 @uts.edu.au 
22 Seungkwan Hong. Tel.: +82-2-3290-3322; E-mail: skhong21 @korea.ac.kr

\section{Abstract}

24 The fertilizer-drawn forward osmosis (FDFO) was investigated for treating coal seam gas (CSG) produced water to generate nutrient rich solution for irrigation. Its performance was evaluated and compared with reverse osmosis (RO) in terms of specific energy consumption (SEC) and nutrient concentrations in the final product water. The RO-FDFO hybrid process was developed to further improve FDFO. The results showed that FDFO has the lowest SEC followed by the RO-FDFO and RO processes. The final nutrient concentration simulation demonstrated that the RO-FDFO hybrid process has lower final concentration, higher maximum recovery and lower nutrient loss than the stand alone FDFO process. Therefore, it was suggested that the RO-FDFO is the most effective treatment option for CSG RO brine as well as favorable nutrient supply. Lastly, membrane fouling mechanism was examined in CSG RO brine treatment by FDFO, and the strategies for controlling fouling were critically evaluated. $\mathrm{KNO}_{3}$ exhibited the highest flux decline corresponding to the highest reverse salt flux, while the most severe membrane scaling was observed with calcium nitrate, primarily due to the reverse transport of calcium ions. To control membrane fouling in FDFO process, both physical flushing and chemical cleaning were examined. Membrane cleaning with citric acid of 5\% resulted in a complete flux recovery.

Keywords: CSG produced water, Fertilizer-drawn forward osmosis, Specific energy consumption, FDFO simulation, Membrane cleaning. 
$47 \quad A$

$48 \quad B$

$49 \quad C_{D, i}$

$50 C_{D, f}$

51

52

$C_{\text {nut }, f}$

53

54

55 Loss $_{\text {Draw }}$

$56 \quad M_{w}$

$57 n$

$58 \quad P_{D}$

$59 \quad P_{F}$

$60 Q_{D}$

$61 Q_{F}$

62

$Q_{P, F D F O}$

$63 Q_{P, R O}$

$64 Q_{P, t o t a l}$

65 Ratio $_{\text {nut }}$
Water permeability coefficient

Salt permeability coefficient

Maximum DS concentration

Final DS concentration having equal osmotic pressure with the initial

FS concentration

Nutrient concentration in the final produced water

Reverse salt flux

Water flux

Draw solute loss at the maximum recovery rate in FDFO

Molecular weight of DS

Number of species

Draw pressure (bar)

Feed pressure (bar)

Draw flow rate $\left(\mathrm{m}^{3} / \mathrm{h}\right)$

Feed flow rate $\left(\mathrm{m}^{3} / \mathrm{h}\right)$

Permeate flow rate $\left(\mathrm{m}^{3} / \mathrm{h}\right)$ in FDFO

Permeate flow rate $\left(\mathrm{m}^{3} / \mathrm{h}\right)$ in RO

Total permeate flow rate $\left(\mathrm{m}^{3} / \mathrm{h}\right)$

Ratio of each nutrient component 
$66 R_{\max }$

67

$68 S$

$69 S E C_{F D F O}$

$70 \quad S E C_{R O}$

$71 S E C_{R O+F D F O}$

$72 S R S F$

$73 \quad T$

$74 \quad V_{D, i}$

$75 \quad V_{D, f}$

$76 V_{\text {ext }}$

77

78 Greek symbol

79

$80 \quad \eta$

81

82 Abbreviation

83

84 CAN

$85 \quad \mathrm{CSG}$

86
Maximum recovery rate in FDFO

Universal gas constant

Structure parameter of the support layer

Specific energy consumption of FDFO

Specific energy consumption of RO

Specific energy consumption of the RO-FDFO hybrid process

Specific reverse salt flux

Temperature

Initial DS volume

Final DS volume

Water extraction capacity

Pump efficiency

Calcium nitrate

Coal seam gas

Di-ammonium phosphate 


\begin{tabular}{|c|c|c|}
\hline 87 & DI & Deionized \\
\hline 88 & DS & Draw solution \\
\hline 89 & EDTA & Ethylenediaminetetraacetic acid \\
\hline 90 & EDX & Energy dispersive x-ray spectroscopy \\
\hline 91 & FDFO & Fertilizer-drawn forward osmosis \\
\hline 92 & FO & Forward osmosis \\
\hline 93 & FS & Feed solution \\
\hline 94 & FSF & Forward salt flux \\
\hline 95 & $\mathrm{ICP}$ & Internal concentration polarization \\
\hline 96 & NF & Nanofiltration \\
\hline 97 & OMBR & Osmotic membrane bioreactor \\
\hline 98 & PA & Polyamide \\
\hline 99 & $\mathrm{RO}$ & Reverse osmosis \\
\hline 100 & SEM & Scanning electron microscopy \\
\hline 101 & SOA & Ammonium sulphate \\
\hline 102 & RSF & Reverse salt flux \\
\hline 103 & SEC & Specific energy consumption \\
\hline 104 & SRSF & Specific reverse salt flux \\
\hline 105 & TFC & Thin-film composite \\
\hline 106 & XRD & X-Ray diffraction \\
\hline
\end{tabular}




\section{0d. Introduction}

Coal seam gas (CSG), which is also known as coal-bed methane, has been widely

110 explored in United States, Australia, Canada, United Kingdom, and other nations since the

111 1970s [1]. During CSG extraction, underground water in the coal seam is pumped to the

112 surface together with methane gas. This is often called CSG produced water, which is

113 dominantly composed of sodium, chloride and bicarbonate [2]. In Australia, the salinity of

114 CSG produced water is relatively low, typically in the range of up to $6,000 \mathrm{mg} / \mathrm{L}$ [3]. Thus,

115 CSG produced water can be treated and utilized for a variety of application including

116 irrigation [4]. Since CSG produced water has a high sodium content (i.e. a high sodium

117 adsorption ratio), utilization of untreated CSG produced water for irrigation can lead to a

118 gradual decrease in the permeability of soil, eventually causing infiltration problems and

119 other form of soil degradation [5]. Therefore, it is necessary to remove sodium to enable

120 reuse of CSG produced water for irrigation.

121 Reverse osmosis (RO) is currently the most widely used technology for CSG

122 produced water treatment (Fig. 1a) due to its several merits such as small footprint, ease of

123 automation, and modular design [6]. However, RO generally exhibits high energy

124 consumption (i.e., typically above $4-5 \mathrm{kWh} / \mathrm{m}^{3}$ for a seawater desalination plant) due to the

125 high hydraulic pressure as a driving force [7]. Moreover, RO is often hampered by high

126 fouling potentential and inherent limitations such as low recovery $[8,9]$. To overcome these

127 issues, forward osmosis (FO) was proposed since it can provide high rejection of

128 contaminants, low fouling propensity, high fouling reversibility and low energy

129 requirement $[10,11]$. However, FO has several limitations including the need to extract 
130 pure water from the diluted draw solution (DS), requiring the additional desalting processes

131 (e.g., nanofiltration (NF), RO or membrane distillation) [12, 13].

132

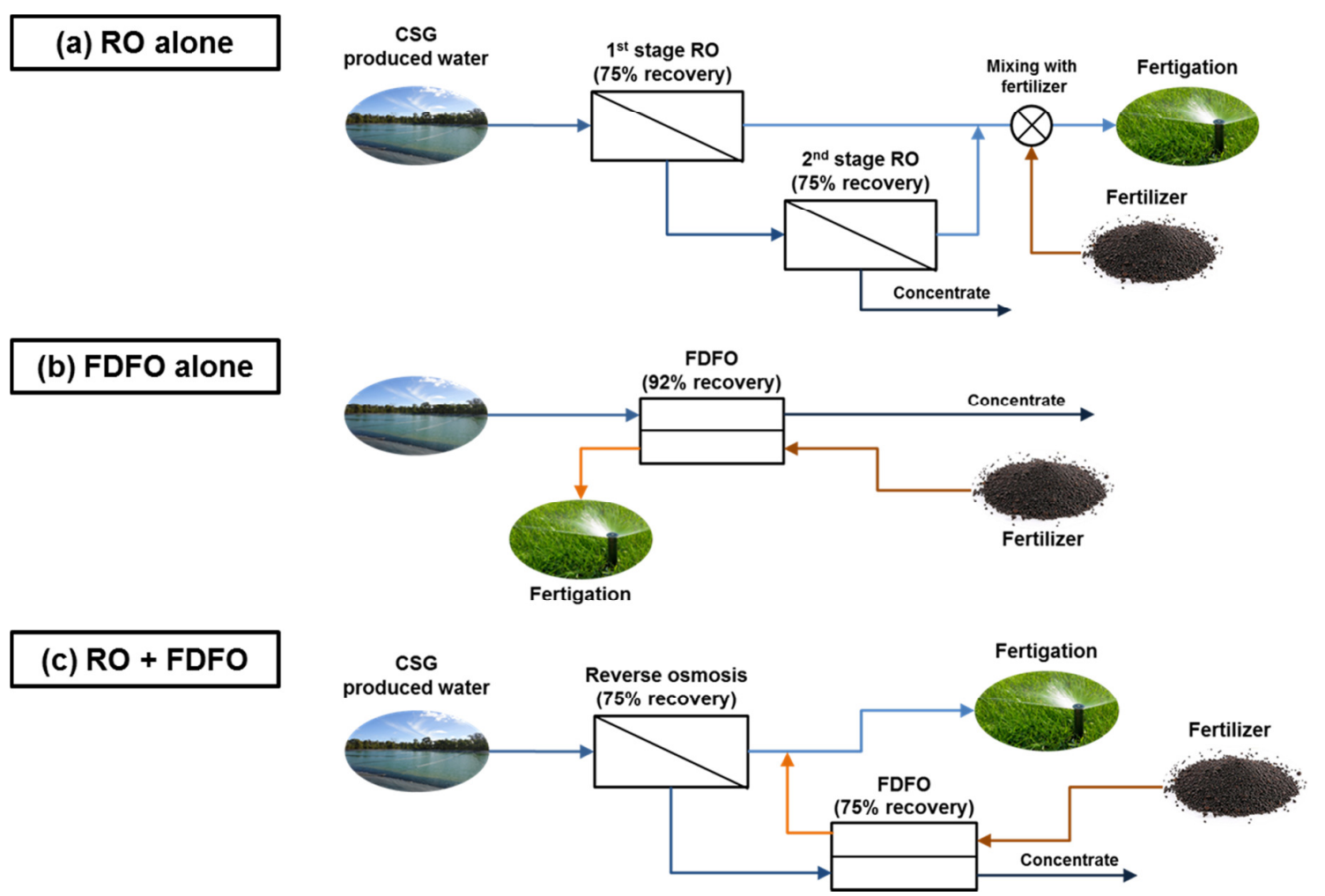

134 Figure 1. Conceptual process layout for integrating RO-FDFO hybrid process: (a) 2 stage

135 RO system, (b) FDFO alone system and (c) RO-FDFO hybrid system.

138 since the diluted fertilizer solution can be utilized directly for irrigation purpose and thus

139 the diluted DS separation and recovery process is not required [14-16]. However the diluted

140 fertilizer solution still required substantial dilution since the final nutrient concentration can

141 exceed the standard nutrient requirements for irrigation especially using feed water sources 
142 with high salinity $[15,16]$. Thus, NF can be employed as a post-treatment process for

143 further dilution and in meeting the water quality requirements for fertigation [14]. However,

144 FDFO is seen to be more suitable for the treatment of low salinity impaired water sources

145 (e.g., CSG produced water, wastewater and so on) as shown in Fig. 1b so that desired

146 fertilizer dilution can be achieved without the need of a NF post-treatment process [17].

147 Since FDFO utilizes highly concentrated fertilizer DS, FDFO has serious problems

148 regarding the reverse solute flux of the draw solute induced by the large concentration

149 differences between the feed solution (FS) and DS across FO membrane. The reverse

150 diffusion of draw solutes to FS in the FDFO process can reduce the recovery rate and lose

151 the valuable fertilizers in DS. In addition, reverse salt flux (RSF), which is reversely

152 diffused draw solute through FO membrane from DS to FS, can alter the feed chemistry

153 and accelerate membrane fouling or scaling [18-20], and inhibit the biological processes in

154 osmotic membrane bioreactor (OMBR) which is one of the potential applications [17, 21].

155 Moreover, because of an increase in FS concentration caused by RSF, direct discharge of

156 FS may entail negative impacts to the environment [22], which requires further treatment of

157 FS concentrate.

158 In order to solve or mitigate these problems (i.e., high energy consumption in RO

159 and valuable fertilizer draw solute loss by RSF in FDFO), a RO-FDFO hybrid process was

160 proposed for simultaneous CSG produced water treatment for the agricultural application

161 based on the concept described in Fig. 1c. This hybrid system consists of two parts (i.e.,

162 RO and FDFO). The $1^{\text {st }}$ stage RO will concentrate CSG produced water by up to $75 \%$ and

163 produce clean water. Then, the $2^{\text {nd }}$ stage FDFO will treat CSG RO brine from the $1^{\text {st }}$ stage 
164 RO and also produce nutrient solution. The diluted fertilizer DS from the FDFO process

165 will be mixed with RO permeate and supplied for fertigation. In this system, CSG produced 166 water will be utilized as an influent and a highly concentrated fertilizer solution will be 167 used as DS for the RO-FDFO hybrid process. The diluted fertilizer solution can then be 168 obtained and supplied to fertigation. Therefore, this study aims to evaluate the feasibility of the RO-FDFO hybrid system

170 for the treatment of CSG produced water and production of nutrient solution by comparing 171 with RO alone and FDFO alone. Comparisons are made based on the specific energy 172 consumptions (SEC) and nutrient concentrations in the final FDFO product water. Finally, 173 membrane scaling and fouling in FDFO during CSG RO brine treatment was evaluated and 174 the cleaning strategies were further investigated using both physical cleaning and chemical 175 cleaning.

\section{Materials and methods}

\section{$178 \quad 2.1 \quad$ FO membrane and draw solutions} FO membrane used in this study was provided by Toray Chemical Korea (South

180 Korea). This membrane was a thin-film composite (TFC) polyamide (PA) FO membrane 181 with an embedded woven mesh for mechanical strength as shown in Fig. S1. The total 182 membrane thickness was approximately $60 \mu \mathrm{m}$. The intrinsic FO membrane characteristics

183 (i.e., the water permeability coefficient (A) and the salt permeability coefficient (B) of the 184 active layer, and the structure parameter (S) of the support layer) were detemined based on 
185 the mathematical method [23] and shown in Table S1. For storage, the membranes were 186 immersed in deionized (DI) water at $4{ }^{\circ} \mathrm{C}$ and the water was replaced regularly. Four different reagent grade chemical fertilizers (i.e., ammonium sulphate (SOA),

188 calcium nitrate $(\mathrm{CAN})$, di-ammonium phosphate (DAP), potassium nitrate $\left.\left(\mathrm{KNO}_{3}\right)\right)($ Sigma 189 Aldrich, Australia) were used as draw solutes. DS was prepared by dissolving fertilizer 190 chemicals in DI water. Detailed information of fertilizer chemicals is provided in Table S2.

191 Osmotic pressure and diffusivity of four fertilizers were obtained by OLI Stream Analyzer 1923.2 (OLI System Inc., Morris Plains, NJ, USA).

\subsection{Coal seam gas reverse osmosis brine} water from Gloucester Basin in the Upper Hunter, New South Wales, Australia. Operation conditions of the pilot plant were as follows: ultrafiltration pre-treatment, $5 \mathrm{mg} / \mathrm{L}$ antiscalant (Osmotreat, Osmoflo, Adelaide, South Australia, Australia), and RO recovery of $75 \%$ [2]. Detail information of CSG RO brine used as FS in this study is provided in Table 1.

Table 1. Water quality of CSG RO brine used in this study. CSG RO brine was collected 203 from a pilot-scale RO system for treating CSG produced water from the Gloucester gas 204 field [24].

\begin{tabular}{l|l|l|l}
\hline General & Values & Ion concentration & Values \\
\hline
\end{tabular}




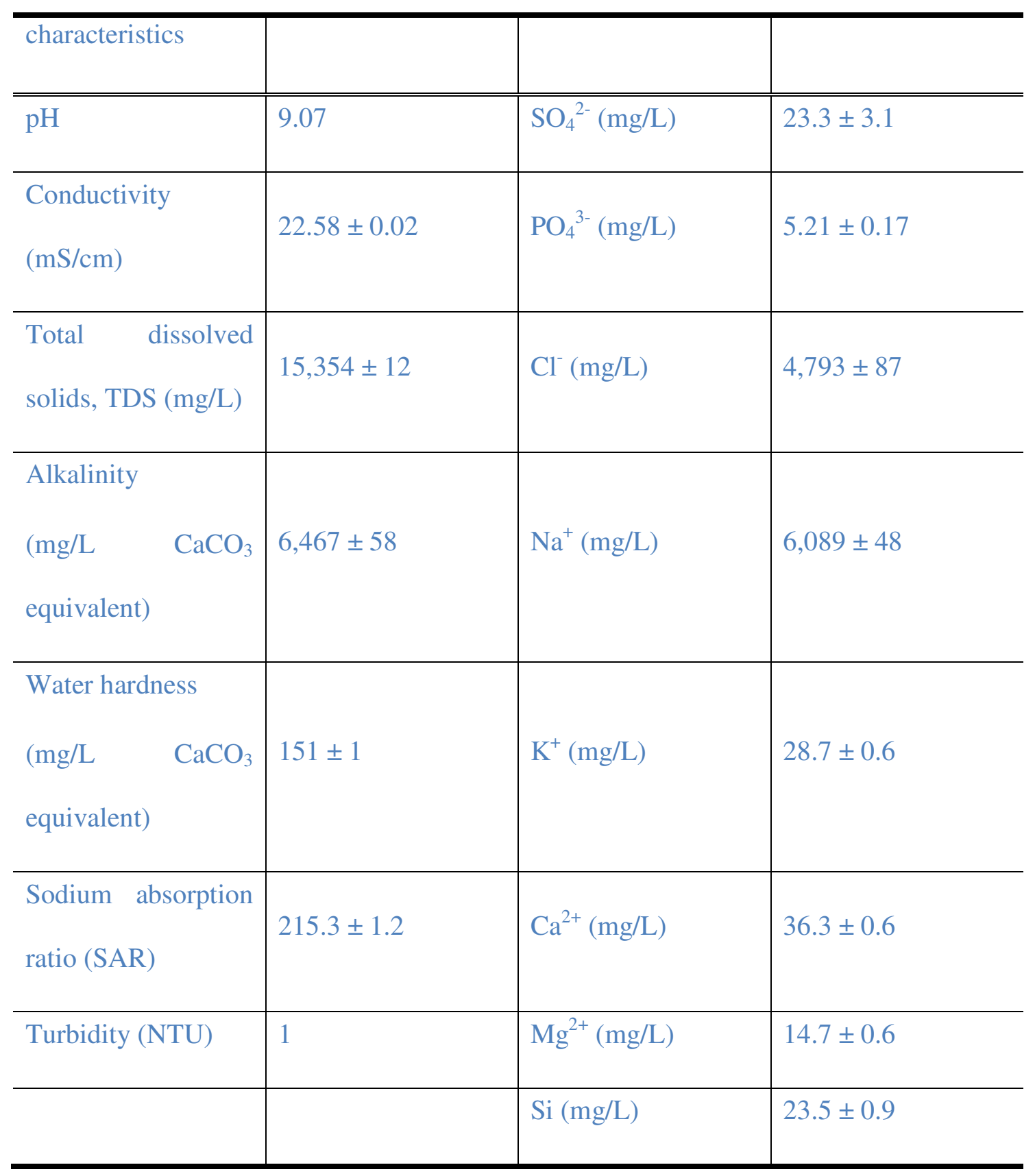




\subsection{Fertilizer-drawn forward osmosis experiments}

\subsubsection{Fertilizer-drawn forward osmosis experiments}

All FDFO experiments were carried out using a lab-scale FO system similar to the one described in our previous studies [25]. The FO cell had two symmetric channels consisting of $77 \mathrm{~mm}$ long, $26 \mathrm{~mm}$ wide and $3 \mathrm{~mm}$ deep on both sides of the membrane each for each FS and DS. Variable speed gear pumps (Cole-Parmer, USA) were used to provide crossflows under counter-current directions at a crossflow rate of $8.5 \mathrm{~cm} / \mathrm{s}$ and solution temperature of $25 \pm 1{ }^{\circ} \mathrm{C}$. All FDFO operations were carried out using $1 \mathrm{M}$ fertilizers as DS and CSG RO brine as FS under the AL-FS (i.e., active layer facing FS) mode of membrane orientation. Both solutions were recirculated in a closed-loop system resulting in a batch mode process operation. The DS tank was placed on a digital weighing scale and the weight changes were recorded by a computer in real time every 3 minutes interval to determine the water flux. Conductivity and $\mathrm{pH}$ meters ( $\mathrm{HACH}$, Germany) were connected to a computer to monitor concentration and $\mathrm{pH}$ changes in the feed tank.

\subsubsection{Physical cleaning}

In order to investigate the effect of physical cleaning on water flux recovery of the FO membrane after fouling, two different physical cleaning methods (i.e., hydraulic washing and osmotic backwashing) were adopted for all FDFO experiments. Hydraulic washing consisted of flushing DI water inside the DS and FS channels at 3 times higher crossflow velocity $(25.5 \mathrm{~cm} / \mathrm{s})$ for 30 minutes. Osmotic backwashing was conducted for 30 minutes by flushing $1 \mathrm{M} \mathrm{NaCl}$ DS solution on the active layer side of the membrane and DI water on the support layer side (both at $8.5 \mathrm{~cm} / \mathrm{s}$ crossflow velocity) (AL-DS mode of 
membrane orientation) in order to provide water flux in reverse direction to the fouling experiments. Water recovery rate was determined by comparing the baseline water flux of the virgin FO membrane conducted before the CSG RO brine treatment and after the 231 physical cleaning using $1 \mathrm{M} \mathrm{NaCl}$ as DS and DI as FS.

232

\subsubsection{Chemical cleaning}

To investigate the effect of chemical cleaning on water flux recovery, three different chemical cleaning agents (1 mM ethylenediaminetetraacetic acid (EDTA) [26], $1 \mathrm{mM}$ sodium hydroxide $(\mathrm{NaOH})$ [27] and 1-5\% citric acid [28]) were adopted. Chemical cleaning consisted of flushing a cleaning agent inside the FS channel and DI water inside the DS channel at the same crossflow velocity $(8.5 \mathrm{~cm} / \mathrm{s})$ for 30 minutes. Water recovery rate was determined by comparing the baseline water fluxes of the virgin FO membrane and membrane after chemical cleaning using $1 \mathrm{M} \mathrm{NaCl}$ as DS and DI as FS.

\subsection{Membrane surface characterization}

The surfaces of FO membranes were observed and analysed by scanning electron microscopy (SEM, Zeiss Supra 55VP, Carl Zeiss AG, Germany) and energy dispersive Xray spectroscopy (EDX) following the procedures described in a previous study [29]. Samples taken from each membrane were first lightly coated with Au/Pd. The SEM imaging was carried out at an accelerating voltage of $10 \mathrm{kV}$ and multiple image magnifications at various areas were taken for each sample.

X-Ray diffraction (XRD) (Siemems D5000, USA) analysis was also performed over Bragg angles ranging from $10^{\circ}$ to $60^{\circ}(\mathrm{Cu} \mathrm{K} \alpha, \lambda=1.54059 \AA)$ to investigate the dominant species responsible for scaling formed on the membrane surface. Membrane samples 
collected after experiments were first soaked in DI water for a few minutes to remove any

251 feed or draw solutes and then dried in a desiccator for 1 day before SEM imaging was 252 measured.

\section{$253 \quad 2.5 \quad$ Specific energy consumption (SEC) estimation}

Energy consumptions of the three processes (i.e., RO, FDFO and RO-FDFO hybrid process) were estimated in terms of SEC. ROSA 9.1 software (DOW FILMTEC, USA) was used to estimate SEC of RO alone. SEC of the FDFO standalone process was estimated based on the following equiation [30]:

$S E C_{F D F O}=\frac{P_{F} Q_{F}+P_{D} Q_{D}}{36 \times \eta \times Q_{P}}$

where, $P_{F}$ is the feed pressure (bar), $P_{D}$ is the draw pressure (bar), $Q_{F}$ is the feed flow rate $260\left(\mathrm{~m}^{3} / \mathrm{h}\right), Q_{D}$ is the draw flow rate $\left(\mathrm{m}^{3} / \mathrm{h}\right), Q_{P}$ is the permeate flow rate $\left(\mathrm{m}^{3} / \mathrm{h}\right)$ and $\eta$ is the 261 pump efficiency. The total SEC in the RO-FDFO hybrid process is the sum of the energy consumption as shown in Eq. (2).

$S E C_{R O+F D F O}=\frac{S E C_{R O} Q_{P, R O}+S E C_{F O} Q_{P, F D F O}}{Q_{P, \text { total }}}$

264 where, $\mathrm{Q}_{P, \text { total }}, \mathrm{Q}_{P, R O}$ and $\mathrm{Q}_{P, F D F O}$ are the total permeate flow rate $\left(\mathrm{m}^{3} / \mathrm{h}\right)$, the permeate flow 265 rate $\left(\mathrm{m}^{3} / \mathrm{h}\right)$ in $\mathrm{RO}$ and the permeate flow rate $\left(\mathrm{m}^{3} / \mathrm{h}\right)$ in FDFO, respectively. It should be 266 noted here that, for SEC estimation of both RO and FDFO, RO membrane, FS, the pump 267 efficiency and the feed and draw pressure in FDFO alone were assumed to be BW30-4040 268 (Dow Filmtec, USA), CSG produced water [2], 80\% and 1 bar, respectively. BW30-4040 is 269 a brackish water RO membrane with high salt rejection. If CSG produced water contains 
high concentration of organics, the viscosity will be seriously increased as the CSG 271 produced water is concentrated, which can result in a significant reduction in the pump 272 efficiency. However, since CSG produced water has quite low concentration of organics 273 (e.g., $1.7 \mathrm{mg} / \mathrm{L}$ TOC) [2], the pump efficiency can be assumed to be constant as $80 \%$.

\section{4}

\subsection{Final nutrient concentration simulation}

Nutrient concentrations in the final product water can be simulated using the water extraction capacity $\left(V_{e x t}\right)$ of $1 \mathrm{~kg}$ DS $[15,31]$. This equation was derived under counter current crossflow mode with an assumption of no forward salt flux (FSF) and no RSF.

$$
V_{\text {ext }}=\frac{1000}{M_{W}}\left[\frac{1}{C_{D, i}}-\frac{1}{C_{D, f}}\right]
$$

where, $M_{w}$ is molecular weight of DS, $C_{D, i}$ is the maximum DS concentration (solubility) and $C_{D, f}$ is the final DS concentration having equal osmotic pressure with the initial FS concentration. In the FO process, RSF could have a significant impact on the FO process by increasing the FS concentration and decreasing the DS concentration, resulting in lower effective osmotic driving force. However, the effect of RSF on the FDFO process was not considered for Eq. (3) and thus, the water extraction capacity by Eq. (3) is likely to be over-estimated. In this study, therefore, Eq. (3) was modified by adopting the definition of specific reverse salt flux (SRSF) as follows.

$$
V_{\text {ext }}=\frac{1-\left(\frac{C_{D, f}}{C_{D, i}}\right)}{\left(\frac{C_{D, f} M_{W}}{1000}\right)+S R S F}
$$

where SRSF is defined as the ratio of RSF to water flux in the FO process as presented in Eq. (5). The SRSF is independent of membrane support layer properties and 
can quantitatively elucidate FO membrane performance [25]. Here, we assumed that SRSF

291 is constant without any change even though membrane fouling occurs during operation.

$292 \frac{J_{s}}{J_{w}}=\frac{B}{A} \frac{1}{n R_{g} T}$

293 where, $n$ is the number of species that the draw solute dissociates into, $A$ is the water

294 permeable coefficient, $B$ is the salt permeable coefficient, $R_{g}$ is the gas constant, and $T$ is

295 the temperature. Nutrient concentrations in the final produced water can be obtained by 296 using Eq. (6). This equation was derived from mass balance for draw solute.

$297 C_{n u t, f}=\frac{1-S R S F \times V_{\text {ext }}}{V_{D, f}} \times$ Ratio $_{\text {nut }}$

298 where, Ratio $_{n u t}$ is the ratio of each nutrient component and $V_{D, f}$ is the final DS volume.

299 Based on Eq. (4), the draw solute loss and the maximum recovery rate of FDFO can be also 300 obtained as Eq. (7) and Eq. (8), respectively.

$301 \quad \operatorname{LoSS}_{\text {Draw }}=\frac{S R S F \times V_{\text {ext }}}{C_{D, i} V_{D, i}} \times 100 \%$

$302 R_{\max }=\frac{Q_{F}-V_{e x t}}{Q_{F}}$

303 where, $\operatorname{Loss}_{\text {Draw }}$ is the draw solute loss at the maximum recovery rate in FDFO, $V_{D, i}$ is the 304 initial DS volume and $R_{\max }$ is the maximum recovery rate in FDFO.

\section{Results and discussion}


308 forward osmosis and reverse osmosis - fertilizer-drawn forward osmosis hybrid 309 processes for coal seam gas produced water treatment

311 processes) for treating CSG produced water and the supplying nutrient solution for 312 irrigation are presented as a function of feed recovery rates (\%) in Fig. 2. The efficiency of 313 the high pressure pump for RO and the circulation pump for FDFO was assumed at $80 \%$ 314 and the applied pressure for circulating FS and DS in FDFO was set at 1 bar [30]. 315

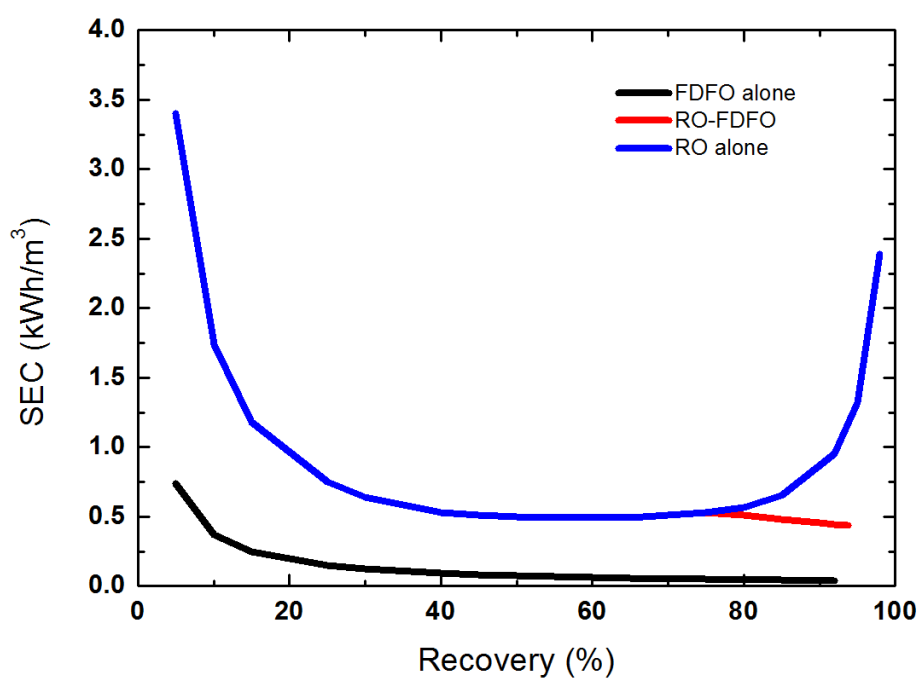

317 Figure 2. SEC evaluation of RO alone, FDFO alone and RO-FDFO hybrid processes as a 318 function of recovery rate (\%). The estimated SEC results are defined as overall energy 319 consumption $(\mathrm{kWh})$ per produced water $\left(\mathrm{m}^{3}\right)$. The flow rate in FS for all processes and the 320 working pressure for FDFO operation were assumed to be $20 \mathrm{~m}^{3} / \mathrm{d}$ and 1 bar, respectively. 
In RO alone, the SEC significantly reduced from $3.5 \mathrm{kWh} / \mathrm{m}^{3}$ to $0.7 \mathrm{kWh} / \mathrm{m}^{3}$ by increasing the feed recovery rate of up to $75 \%$ beyond which the SEC started to increase rapidly. This is due to the significant increase in hydraulic pressure needed to overcome the increased osmotic pressure of the feed concentrate along the fee channel. For example, osmotic pressure increases 4 times when recovery rate reaches up to $75 \%$ against 2 times increase at 50\% recovery rate. The reults in Fig 2 indicates that, the osmotic pressure of feed concentrate increases exponentially with the recovery rates above $75 \%$ thereby signficantly increasing the hydraulic pressure needed to overcome this enhanced osmotic pressure.

The SEC of the FDFO process alone shows that, the SEC continuously reduced 334 with increasing recovery rate. In the RO process, the hydraulic driving force incresed with the recovery rates due to increase in the the osmotic pressure of the feed and its concentrate thereby incresaing the SEC. However, in the FDFO process, the driving force and the feed recovery rates can be simply increased by increasing the initial DS concentration without

338 impacting the hydraulic pressure and SEC of the process [32]. Consequently, FDFO has 339 much lower SEC than RO due to its lower hydraulic operatiing pressure, consistent with 340 other studies [30, 33].

341 Lastly, FDFO was combined with RO as shown in Fig. 1c to increase the overall 342 feed recovery rate without signficantly impacting on the SEC. As discussed above, when 
343 the RO process is used alone, it was found that SEC increased rapidly with feed recovery 344 rates above $75 \%$. When FDFO is combined with RO for the treatment of its brine after $75 \%$ 345 recovery rate, the overall recovery rate can be signficantly increased without much impact 346 on the total energy consumption or the combined SEC. Simulation results showed that SEC 347 of the RO-FDFO combined process continuously decreased even up to $95 \%$ recovery rate. 348 Based on all the SEC simulation results above, it can be concluded that FDFO alone is the 349 most economic process followed by the RO-FDFO hybrid process and RO alone.

forward osmosis and reverse osmosis - fertilizer-drawn forward osmosis hybrid processes

The RO process alone produces pure water with a quality that is generally suitable 355 for direct irrigation with or without remineralisation. Since the FDFO process alone does not generate pure water, their final water quality must be assessed against key irrigation criteria. For comparison, FDFO alone and the RO-FDFO hybrid process were selected and compared in terms of final nutrient concentration, draw solute loss, and maximum recovery rate.

Before the simulation, SRSF was experimentally measured and presented in Table.

361 S3. Results show that SOA had the lowest SRSF followed by DAP, CAN and $\mathrm{KNO}_{3}$. With 362 regards to water flux, $\mathrm{KNO}_{3}$ showed the highest water flux followed by SOA, CAN and 363 DAP, which is not consistent with osmotic pressures of fertilizers (Table S2). This 364 difference in water flux between fertilizers is explained from the variations of the extent of 
365 ICP effects induced by the mass transfer resistance $(\mathrm{K})$ within the membrane support layer.

366 Since mass transfer resistance refers to the ratio between the $S$ parameter and diffusivity of

367 DS, a draw solute with higher diffusivity has low mass transfer resistance and should have

368 high water flux $[17,25]$. In terms of RSF, SOA exhibited the lowest RSF followed by DAP,

$369 \mathrm{CAN}$ and $\mathrm{KNO}_{3}$. Unlike the water flux, the trend for RSF with diffusivity was quite

370 different. This is because RSF is theoretically a function of not only the effective

371 concentration gradient across the active layer of the FO membrane but also the salt

372 rejecting properties of the membrane $[17,34]$. As a consequence, SRSF of fertilizer DS was

373 determined by the salt permeable coefficient (B value) which varies with fertilizers. From

374 these results, it can be drawn that SOA is possibly the optimum fertilizer DS in terms of

375 draw solute loss and maximum recovery rate since it has the smallest draw solute loss with

376 the same volume of feed water extraction.

377 The draw solute loss and the maximum recovery rate of both FDFO and RO-FDFO

378 hybrid processes were firstly simulated using Eq. (7) and Eq. (8), respectively and

379 presented in Fig. 3. As expected, in FDFO process, $\mathrm{KNO}_{3}$ exhibited the highest draw solute

380 loss followed by DAP, CAN and SOA (Fig. 3a). It is interesting to note that DAP showed

381 higher draw solute loss than CAN in spite of its lower SRSF. This is because the draw

382 solute loss is affected by both the extraction capacity and SRSF as shown in Eq. (7),

383 indicating that higher extration capacity of DAP also induced higher draw solute loss.

384 Results of Fig. 3b indicated that maximum recovery rates of both processes have the totally

385 a different trend with SRSF. 

followed by $\mathrm{SOA}, \mathrm{KNO}_{3}$ and $\mathrm{CAN}$. This different trend between draw solute loss and maximum recovery rate was originated from their different dominant mechanisms. As we discussed above, draw solute loss was dominantly determined by both SRSF and recovery rate. However, maximum recovery rate was obtained from the extraction capacity of 391 fertilizer DS which is affected by osmotic pressure of fertilizer DS. For example, as shown 392 in Eq. (4), if DS has high osmotic pressure at low concentration, its water extraction 393 capacity will be high based on osmotic equillibrium and thus total recovery rate will be 394 high. Similarly, since DAP has the highest osmotic pressure among fertilizers, DAP 395 exhibitied the highest maximum recovery rate in spite of its high SRSF. Results from Fig. 3 396 show that, to achieve low draw solute loss and high maximum recovery rate in FDFO, 397 fertilizer DS should have low SRSF and high osmotic pressure.
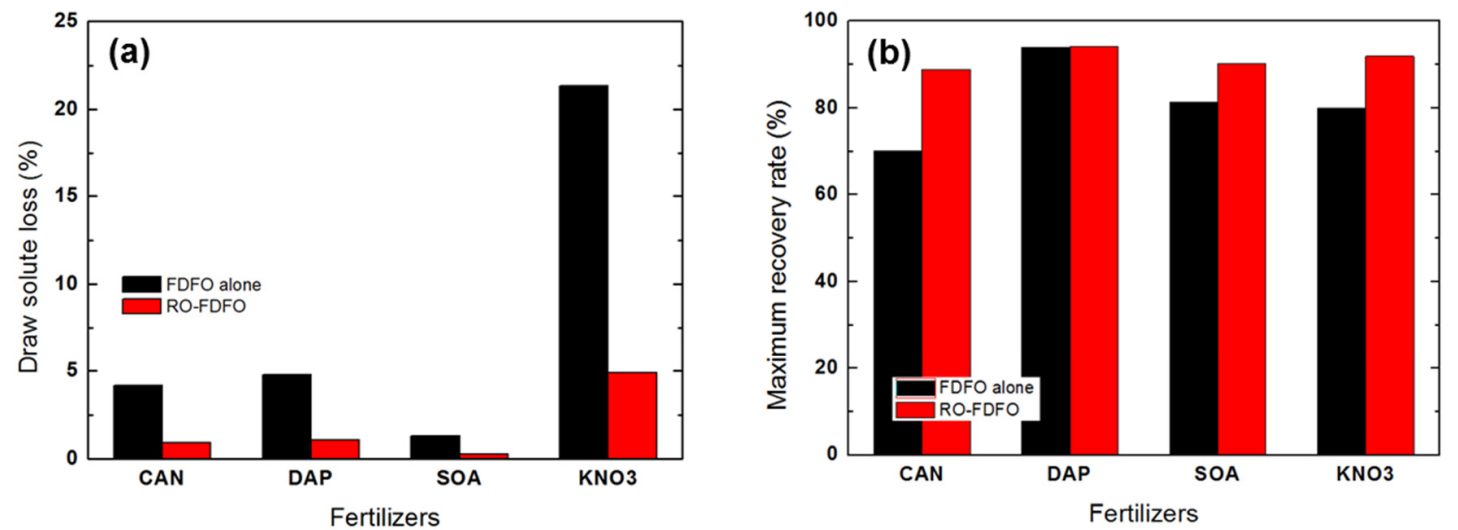

400 Figure 3. Comparative performances of FDFO and integrated RO-FDFO processes in 401 terms of (a) draw solute loss and (b) maximum water recovery rate. 
404 draw solute loss and higher maximum recovery rate with all fertilizers. In the RO-FDFO 405 hybrid process, RO produced $75 \%$ of the feed as clean water while the FDFO process was used to further extract water only from the concentrate to increase the overall feed recovery rate to $95 \%$. Therefore, the amount of the extracted water from the feed water by FDFO process in the hybrid system was lower than that in FDFO alone. As a result, the draw solute loss in the RO-FDFO hybrid process was much lower than that in FDFO. However, the RO-FDFO hybrid process exhibited higher maximum recovery rate than FDFO alone 411 and this difference is likely induced by the difference of draw solute loss during the FDFO 412 processes. In the FDFO process, the higher amount of draw solute was lost to the FS and 413 thus the concentration of diluted DS could reached faster to its concentration that has equal 414 osmotic pressure as the inital FS, resulting in a lower maximum recovery rate. It is very 415 interesting to note that the trend of the maximum recovery rate between FDFO and the the 416 RO-FDFO hybrid process was quite different. Although DAP showed the highest maximum recovery rates for both the processes however, other fertilizers showed a 418 different trend. This is because, besides osmotic pressure, SRSF of the fertilizer DS is also 419 an important factor for determining the maximum recovery rate. For example, as recovery 420 rate increases, the loss of draw solute becomes more significant thereby accelerating the 421 reduction of DS concentration resulting in a decrease in the maximum recovery rates. 422 Therefore, by combining RO with FDFO, draw solute loss can be minimized and total 423 recovery rate can be maximized. 
425 in terms of major nutrients (N/P/K) using Eq. (5) to find out which process is more suitable

426 for producing favourable nutrient water for irrigation. Results shown in Table 2 indicate

427 that $\mathrm{KNO}_{3}$ in the FDFO process exhibited the lowest nitrogen concentration followed by

428 DAP, SOA and CAN since $\mathrm{KNO}_{3}$ has the lowest nitrogen content (i.e., 13.85\%) and the

429 highest draw solute loss (Fig. 3a). Although a loss in the draw solute could affect the

430 nutrient concentration however, the final DS concentration is mainly determined by

431 osmotic equilibrium with the initial FS concentration.

432

433 Table 2. Comparative performances of FDFO alone and the integrated RO-FDFO

434 processes in terms of N/P/K nutrient concentrations in the final FDFO product water.

\begin{tabular}{|c|c|c|c|c|c|c|}
\hline Fertilizers & CAN & DAP & & SOA & $\mathrm{KNO}_{3}$ & \\
\hline Nutrients & $\mathrm{N}(\mathrm{mg} / \mathrm{L})$ & $\mathrm{N}(\mathrm{ppm})$ & $\mathrm{P}(\mathrm{ppm})$ & $\mathrm{N}(\mathrm{ppm})$ & $\mathrm{N}(\mathrm{ppm})$ & $\mathrm{K}(\mathrm{ppm})$ \\
\hline $\begin{array}{l}\text { FDFO } \\
\text { alone }\end{array}$ & 268.40 & 201.19 & 222.45 & 230.63 & 114.76 & 320.33 \\
\hline $\begin{array}{l}\text { RO-FDFO } \\
\text { hybrid }\end{array}$ & 199.25 & 186.55 & 206.26 & 194.31 & 93.98 & 262.34 \\
\hline
\end{tabular}

When considering recommended concentrations $(\mathrm{N} / \mathrm{P} / \mathrm{K})$ for beneficial plants (e.g.,

$437200 / 50 / 300 \mathrm{ppm}$ for a tomato, 170/60/200 ppm for an eggplant and 200/50/200 ppm for a

438 cucumber) [16], Table 2 indicates that the final product water from the FDFO process 
could satisfy the recommended nitrogen concentration, however, still required substantial 440 dilution to reduce the phosphorous and potassium content.

Simulation results show that the RO-FDFO hybrid process has lower final nutrient

442 concentrations than the product water from the FDFO alone, making it more favourable for 443 direct fertigation. This was because, the FDFO process was used for treating only $25 \%$ of 444 the feed water in the form of RO brine and the further dilution was achieved by blending 445 the RO permeate and the diluted DS from the FDFO process. Although the RO-FDFO 446 hybrid process could reduce final nutrient concentration significantly and make more 447 favourable for fertigation compared to the FDFO process alone however, substantial 448 dilution is still required to meet the recommended concentration, especially in terms of 449 phosphorous nutrient concentraion. However, by controlling the composition of blended 450 fertilizers, the problem regarding exceeding the recommended concentrations can be solved 451 [16]. For example, if we consider a simple combination for only two different fertilizers 452 (i.e., DAP and $\mathrm{KNO}_{3}$ ) with a molar ratio of 1:2.5, the final DS grade can achieve about $453120 / 60 / 190 \mathrm{mg} / \mathrm{L}$, which is quite suitable for growing an eggplant even though the 454 concentration of nutrients should be slightly adjusted. Based on the simulation results of 455 SEC and final nutrient concontrations, the RO-FDFO hybrid process can be considered as 456 the most suitable process for both CSG produced water treatment and favourable nutrient 457 water supply. Therefore, feasibility of the RO-FDFO hybrid process for treating CSG 458 produced water was further investigated in this study. Since CSG produced water treatment 459 by RO was already studied in the previous study [2], we focused on CSG RO brine 
460 treatment by the $2^{\text {nd }}$ stage FDFO process and assessed its performance in terms of water 461 flux, flux decline and the cleaning requirements.

$463 \quad 3.3 \quad$ Flux decline in fertilizer-drawn forward osmosis during coal seam gas reverse 464 osmosis brine treatment

465 The FDFO experiments were carried out with CSG RO brine as FS and four 466 different fertilizers as DS under the AL-FS mode and their flux data is presented in the 467 form of normalized water flux in Fig. 4. $\mathrm{KNO}_{3}$ exhibited the highest flux decline during 1 468 day operation followed by CAN, SOA and DAP. This is because FS conductivity with $469 \mathrm{KNO}_{3}$ was rapidly increased from $21.29 \mathrm{mS} / \mathrm{cm}$ to $40.9 \mathrm{mS} / \mathrm{cm}$ as presented in Table S4 470 due to its highest draw solute loss by RSF (Table S3) even though $\mathrm{KNO}_{3}$ exhibited the 471 lowest accumulated permeate volume. The flux decline could also be caused by more 472 severer membrane fouling but based on the SEM images of the membrane surface with $473 \mathrm{KNO}_{3}$, it was observed that the membrane surface was only partially covered by foulant 474 deposits as shown in Fig. 5d. Thus, it can be concluded that the severest flux decline with $475 \mathrm{KNO}_{3}$ is due to significant decrease in the osmotic driving force caused by the loss of draw 476 solutes towards the FS. 


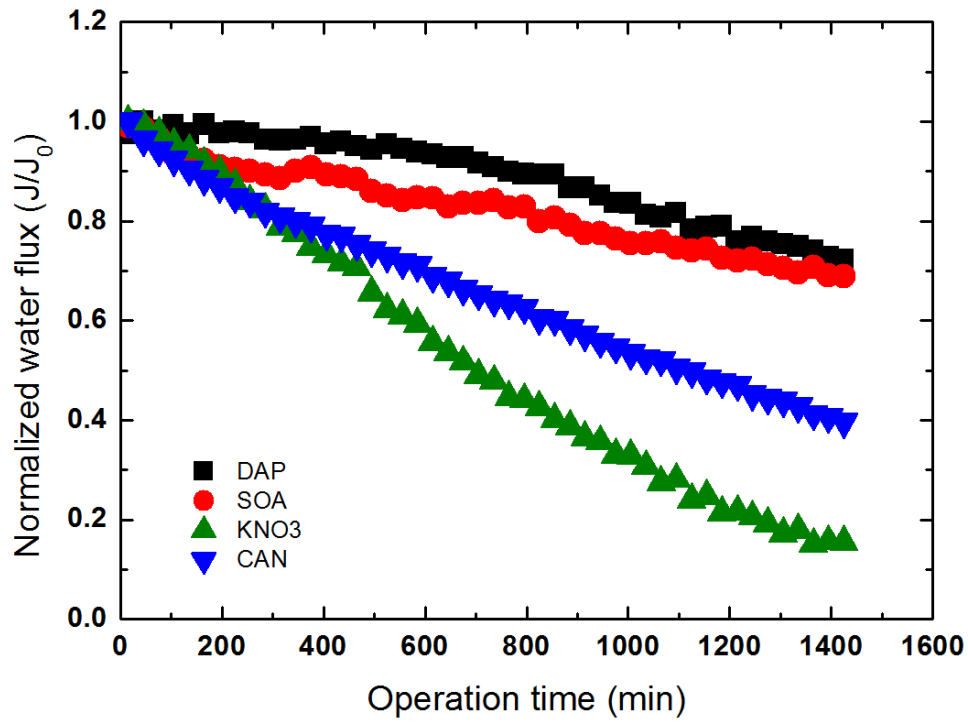

479 Figure 4. Flux-decline curves obtained during FO experiments with four different fertilizer

480 DS. Experimental conditions of all FO experiments: CSG RO brine as FS; four different 481 fertilizers as DS; crossflow velocity of $8.5 \mathrm{~cm} / \mathrm{s}$; and temperature of $25 \pm 1{ }^{\circ} \mathrm{C}$. All FDFO 482 experiments were conducted repeatedly.

483 


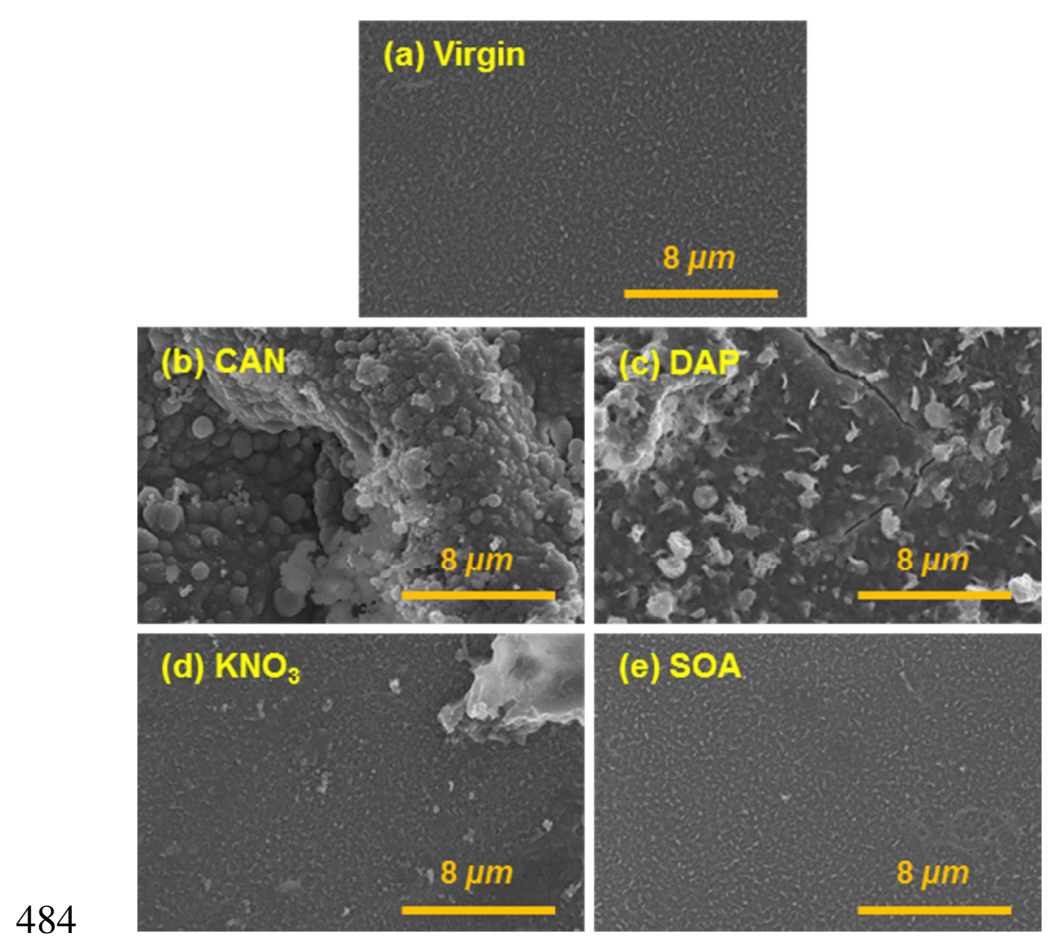

485 Figure 5. SEM images of (a) virgin membrane and fouled membrane with of (b) CAN DS, (c) DAP DS, (d) $\mathrm{KNO}_{3}$ DS and (e) SOA DS.

CAN exhibited the second highest flux decline which is likey due to both an 489 increase in salinity in the FS and membrane fouling. Table S4 showed that FS conductivity 490 with CAN significantly increased from $20.63 \mathrm{mS} / \mathrm{cm}$ to $31.6 \mathrm{mS} / \mathrm{cm}$, resulting in a 491 reduction in the concentration gradient between FS and DS. In addition, Fig. 5b revealed 492 that the surface of FO membrane with CAN was covered by thick scaling layer, the likely 493 main cause of the severe flux decline. When comparing SOA with DAP, it is interesting to 494 note that DAP exhibited lower flux decline even though severer membrane fouling seems 495 to have occurred on the membrane surface with DAP as shown in Fig. 5c. As shown in Fig. 496 5e, no apparent fouling layer was however observed on the membrane surface with SOA as 
DS. A lower flux decline with DAP as DS may be due to lower feed recovery rate with DAP as its FS conductivity increased only slightly from $20.84 \mathrm{mS} / \mathrm{cm}$ to $26.3 \mathrm{mS} / \mathrm{cm}$ while that with SOA increased from $20.58 \mathrm{mS} / \mathrm{cm}$ to $28.5 \mathrm{mS} / \mathrm{cm}$.

From these results, it can be concluded that an increase in FS concentration (batch

501 process) and a decrease in DS concentration due to the loss by RSF were the dominant 502 factor affecting the flux decline in the FDFO process even though membrane fouling layer 503 was formed on the membrane surface with some fertilizers. It is interesting to compare experimental SRSF without a fouling layer with the change in the FS conductivity in terms of specific conductivity increment which is defined as a ratio of the difference between initial and final conductivities to accumulated permeate volume. $\mathrm{KNO}_{3}$ showed the highest specific FS conductivity increment followed by CAN, SOA and DAP, while $\mathrm{KNO}_{3}$ exhibited the highest SRSF followed by CAN, DAP, SOA. $\mathrm{KNO}_{3}$ and CAN showed the similar trend since they had very high SRSF while on the other hand, DAP and SOA with quite low SRSF had the different trend, implying that the fouling layer can have an impact on reducing SRSF in FDFO.

To identify the scaling layer formed on the membrane surface with a variety of 513 fertilizer DS, XRD analysis was carried out on the fouled/scaled membrane surface and presented in Fig. 6a. Results show that the membrane with $\mathrm{KNO}_{3}$ and SOA has similar XRD peaks to the virgin membrane, indicating that no scaling layer was formed on the membrane surface, consistent with SEM analysis results (Fig. 5d and 5e). As shown in Table 1, CSG RO brine is composed of various scaling precursors including calcium, magnesium, phosphate and carbonate ions, indicating that CSG RO brine has high scaling 
potential. Thus, membrane scaling can be formed on the membrane surface when CSG RO brine is highly concentrated [35]. Furthermore, since $\mathrm{KNO}_{3}$ and SOA did not contain any scaling precursor, RSF could not affect membrane scaling formation as depicted in Fig. 7a.
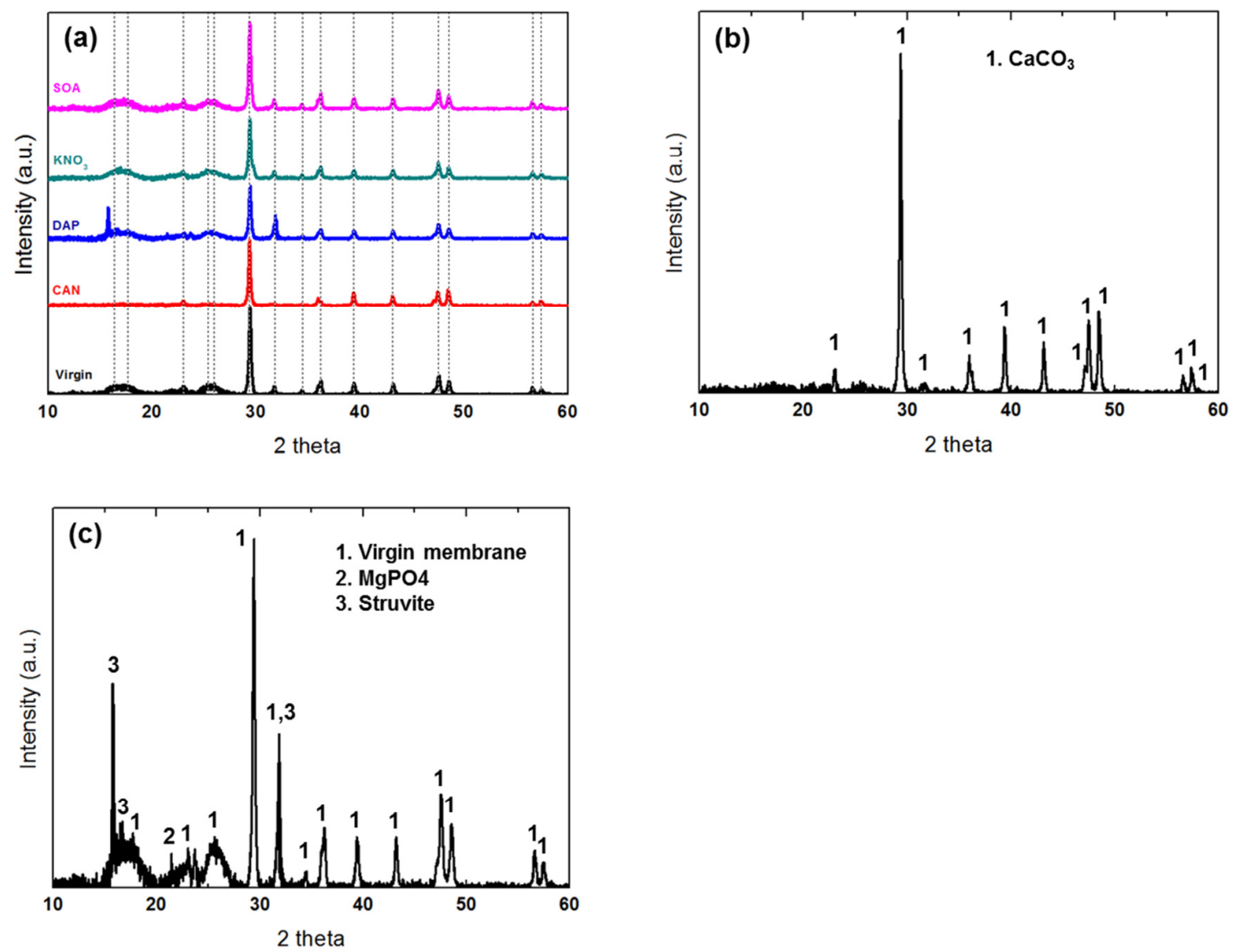

Figure 6. XRD patterns of virgin and fouled membranes: (a) comparison of XRD peaks between virgin membrane and fouled membranes with four different fertilizer DS, (b)

527 comparison of XRD peaks between fouled membranes with $\mathrm{CAN}$ and $\mathrm{CaCO}_{3}$ crystal, and 528 (c) comparison of XRD peaks between fouled membranes with DAP, magnesium 529 phosphate, and magnesium ammonium phosphate (struvite). 


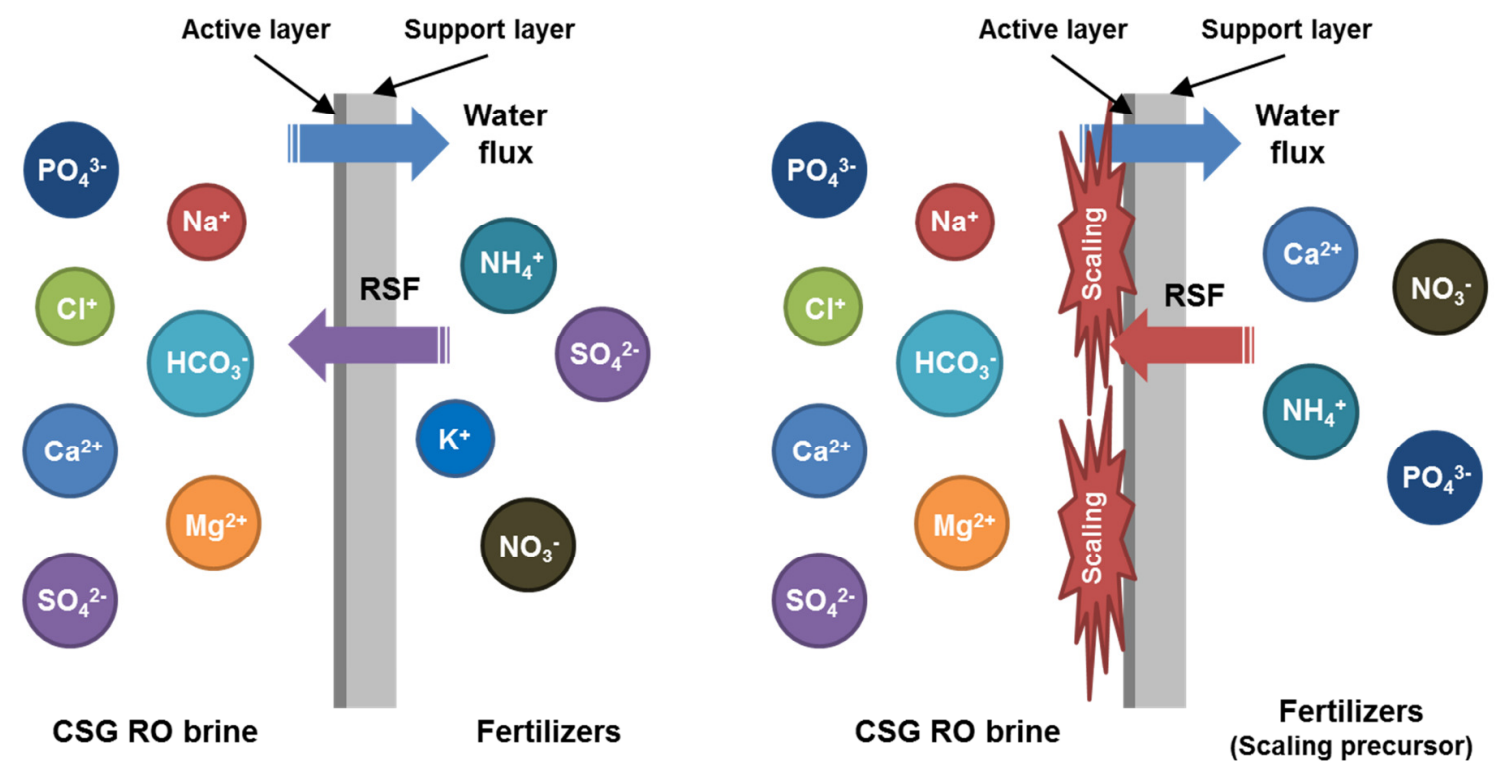

532 Figure 7. Schematic description of FO membrane fouling/scaling during CSG RO brine 533 treatment by FDFO: (a) fertilizers (i.e., $\mathrm{SOA}$ and $\mathrm{KNO}_{3}$ ) without scaling precursors, and (b) 534 fertilizers (i.e., CAN and DAP) with scaling precursors. On the other hand, the XRD pattern for the membrane surface with DAP and CAN 537 exhibited slightly different peaks compared to the virgin FO membrane. For FO membrane used with CAN, most XRD peaks were identical to virgin membrane but some peaks were not visible and some new peaks appeared suggesting that these XRD peaks likely 540 originated from the membrane scaling layer, not the membrane surface. Since calcium was 541 found from EDX analysis (data not shown), XRD peaks with CAN were compared with 542 reference peaks of calcium carbonate (Fig. 6b) which agreed very well indicating the 543 presence of $\mathrm{CaCO}_{3}$ scaling on the membrane surface. Since magnesium and phosphorous 544 were also found from EDX analysis (data not shown), XRD peaks with DAP were also 545 compared with reference peaks of magnesium phosphate and struvite (Fig. 6c). Results 
agreed with struvite, indicating that the scaling layer was primarily composed of struvite.

547 These results suggested that the membrane scaling is significantly affected by draw solute 548 containing scaling precursors such as calcium and phosphate as shown in Fig. $7 \mathbf{b}$. Due to 549 the high concentration gradient, draw solute with a scaling precursor can pass through FO 550 membrane and accelerate ions concentration on the membrane surface [36]. If this exceeds 551 its solubility limits such as of calcium carbonate, magnesium phosphate and struvite, it 552 results in the formation of scales on the membrane surface contributing to flux decline. 553 Besides, the reversely diffused draw solutes can interact with certain ions in FS and induce 554 the formation of a scaling layer [37]. As a result, calcium carbonate and struvite were 555 dominantly formed on the membrane surface with CAN and DAP, respectively. It is very interesting to note that struvite was formed on the FO membrane with 557 DAP DS rather than $\mathrm{Ca}_{3}\left(\mathrm{PO}_{4}\right)_{2}$ and $\mathrm{Mg}_{3}\left(\mathrm{PO}_{4}\right)_{2}$ even though their solubility product 558 constants are much lower than struvite. $\mathrm{Ca}^{2+}, \mathrm{Mg}^{2+}$ and $\mathrm{PO}_{4}{ }^{3-}$ ions are required for the 559 formation of $\mathrm{Ca}_{3}\left(\mathrm{PO}_{4}\right)_{2}$ and $\mathrm{Mg}_{3}\left(\mathrm{PO}_{4}\right)_{2}$, while $\mathrm{HPO}_{4}{ }^{2-}, \mathrm{Mg}^{2+}$ and $\mathrm{NH}_{4}{ }^{+}$ions are required for 560 the struvite formation $\left(\mathrm{MgNH}_{4} \mathrm{PO}_{4}\right)$ [20]. However, $\mathrm{NH}_{4}{ }^{+}$and $\mathrm{HPO}_{4}{ }^{2-}$ ions are the dominant 561 species of DAP DS, resulting in their high reverse diffusion to FS. Consequently, struvite is 562 likely formed on the FO membrane with DAP as DS. As well as the effect of RSF on the 563 scaling formation in FS, FSF also can influence the complexation with DS. However, FSF 564 in FDFO is very low compared to other desalting membrane processes (e.g., NF or RO) due 565 to the hindrance effect of RSF on FSF [38]. Thus, the effect of FSF will be very limited. 566 Besides, although the complexation of FS with DS occurs, it can hardly affect the FO 567 performance due to the permeate flow direction from FS to DS. 


\subsection{Strategy for controlling membrane fouling}

The results of membrane physical cleaning show that the water fluxes were fully

571 recovered for FO membrane used with $\mathrm{KNO}_{3}$ and $\mathrm{SOA}$, which are consistent with SEM

572 results (Fig. 8a). Fig S2c and S2d indicated that the membrane fouling layer formed on the

573 active layer could be readily removed by physical or hydraulic washing. This is because, as

574 previously discussed, $\mathrm{KNO}_{3}$ and $\mathrm{SOA}$ have low scaling potential while CAN and DAP

575 exhibited less than $90 \%$ water flux recovery. These poor flux recovery rates (i.e., $82.3 \%$

576 and $86.6 \%$, respectively) of FO membrane operated with CAN and DAP show that physical

577 or hydraulic washing was not effective in removing the membrane foulants formed on the

578 active layer. Fig. S2a and S2b confirmed that the membrane fouling layer still remained on

579 the active layer with CAN and DAP.

580
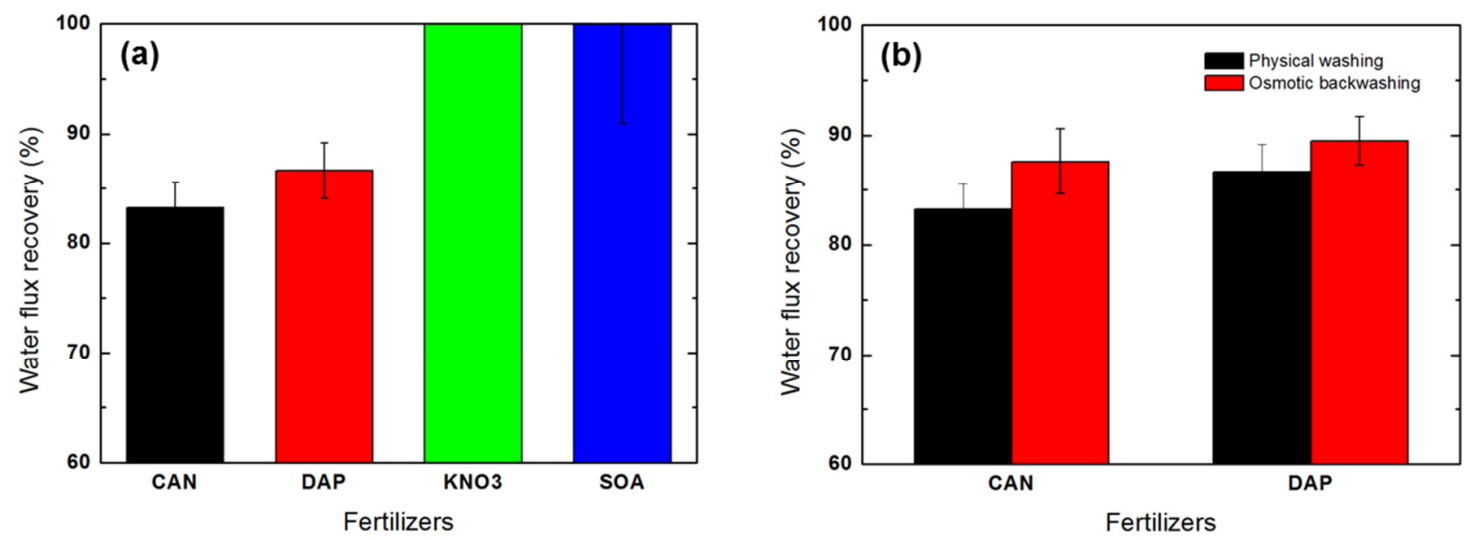

582 Figure 8. Water flux recovery after (a) hydraulic washing and (b) osmotic backwashing.

583 Experimental conditions for hydraulic washing: DI water as FS and DS; crossflow velocity

584 of $25.5 \mathrm{~cm} / \mathrm{s}$; cleaning duration of $30 \mathrm{~min}$; and temperature of $25 \pm 1{ }^{\circ} \mathrm{C}$. Experimental 
conditions for osmotic backwashing: $1 \mathrm{M} \mathrm{NaCl}$ as FS; DI water as DS; crossflow velocity of $8.5 \mathrm{~cm} / \mathrm{s}$; cleaning duration of $30 \mathrm{~min}$; and temperature of $25 \pm 1{ }^{\circ} \mathrm{C}$.

In order to further enhance water flux recovery, osmotic backwashing was applied for the fouled FO membrane with CAN and DAP using DI water on the active layer and 1 $\mathrm{M} \mathrm{NaCl}$ on the support layer side at the same crossflow velocity (i.e., $8.5 \mathrm{~cm} / \mathrm{s}$ for 30 minutes). Fig. 8b shows that water flux recovery was slightly enhanced compared to the hydraulic washing. However, Fig S2e and S2f indicate that the fouling layer on the membrane surface could not be completely removed, which is consistent with the water flux recovery results. The results of the osmotic backwashing agreed well with other studies [19]. However, the results of physical cleaning experiments and SEM images showed that FO membranes with CAN and DAP still require further cleaning.

Chemical cleaning was further investigated for the complete removal of the fouling/scaling layer using three different chemicals (EDTA $1 \mathrm{mM}, \mathrm{NaOH} 1 \mathrm{mM}$ and citric acid 1\%), and the results are presented in Fig. 9a. The fouled FO membrane with CAN was

600 utilized for this study since CAN showed the most severe membrane fouling as well as high

601 flux decline. Fig. 9a demonstrated that $1 \%$ citric acid was more efficienct for recovering 602 water flux compared to the other chemicals (i.e., EDTA $1 \mathrm{mM}$ and $\mathrm{NaOH} 1 \mathrm{mM}$ ). Moreover, 603 SEM images (Fig. S3d) showed that the fouling layer structure was slightly changed by 604 exposure to citric acid 1\%. Citric acid is a weak acid which can dissolve inorganic minerals 605 and be utilized for removing the scaling layer [39]. In addition, citric acid is widely utilized 
606

607

608

609

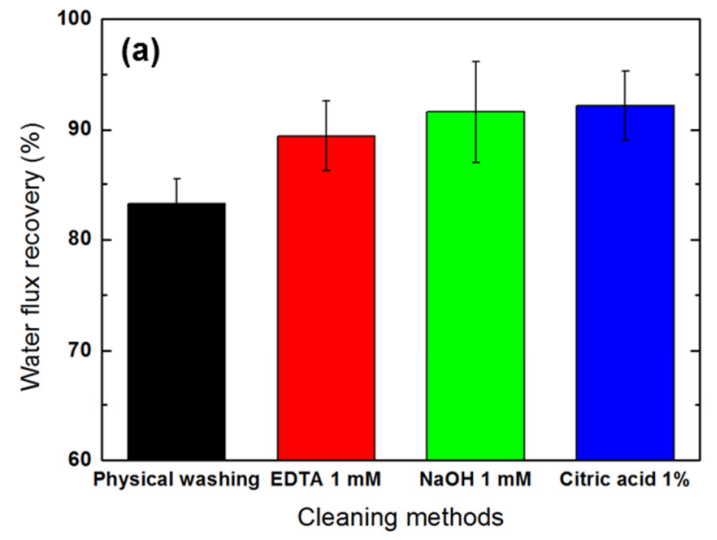

as a chelating agent [40]. Therefore, this can lead to complex with $\mathrm{Ca}^{2+}$ ions, resulting in a reduction of scaling on the membrane surface.

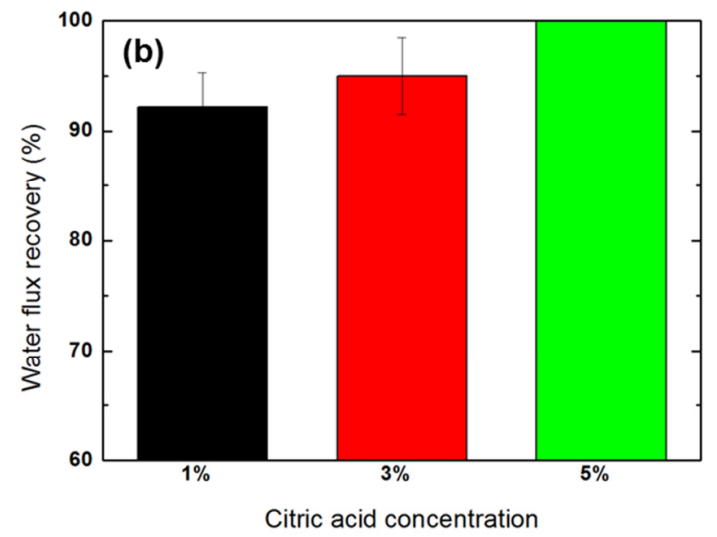

610 Figure 9. Water flux recovery of fouled membrane with CAN after chemical cleaning with

611 (a) varying chemical agents (i.e., EDTA $1 \mathrm{mM}, \mathrm{NaOH} 1 \mathrm{mM}$ and citric acid 3\%) and (b)

612 increasing citric acid concentration. Experimental conditions for chemical cleaning: testing

613 chemical agents as FS; DI water as DS; crossflow velocity of $8.5 \mathrm{~cm} / \mathrm{s}$; cleaning duration of

$61430 \mathrm{~min}$; and temperature of $25 \pm 1{ }^{\circ} \mathrm{C}$.

615

Interestingly, $1 \mathrm{mM}$ EDTA and $1 \mathrm{mM} \mathrm{NaOH}$ showed better cleaning efficiency than

617 hydraulic washing. EDTA is generally utilized for distrupting the fouling layer structure

618 through a ligand exchange between EDTA and organic-divalent complexes [26]. Therefore,

$6191 \mathrm{mM}$ EDTA was effective for removing calcium carbonate scaling, resulting in an increase

620 in water flux recovery [19]. However, Fig. S3b shows that $1 \mathrm{mM}$ EDTA could not remove

621 the scaling layer. $\mathrm{NaOH}$ has been used for dissolving organic foulants in basic solution [27],

622 but it was efficient for recoverying water flux even though the major fouling mechanism 
was membrane scaling enhanced by RSF. This is because CSG RO brine was a mixture of organics and inorganics as shown in Table 1, which can accelerate membrane fouling due to synergistic effects by combined organic-inorganic fouling [41]. Thus, $\mathrm{NaOH}$ could enhance water flux recovery by disolving organics from the combined fouling layer. However, Fig. S3c indicates that the effect of $\mathrm{NaOH}$ on membrane cleaning efficiency is 628 limited.

To further enhance the cleaning efficiency, chemical cleanings were carried out by 630 increasing the citric acid concentration. By increasing the citric acid concentration from $1 \%$ 631 to $3 \%$, the water flux recovery was slightly enhanced (Fig. 9b) and Fig. S3e indicates that 632 there was still some scaling layers on the membrane surface. When the citric acid 633 concentration was further increased to 5\%, water flux was perfectly recovered as shown in

634 Fig. 9b and this was confirmed in Fig. S3f which demonstrates that the fouling layer was 635 completely removed. Since citric acid 5\% exhibited the most efficient cleaning efficiency, 636 fouled FO membrane with DAP was also assessed for its cleaning efficiency using 5\% 637 citric acid as chemical cleaning agent As shown in Fig S3h, it was observed that the 638 membrane surface was completely cleaned as well as water flux was fully recovered (data 639 not shown) with $5 \%$ citric acid chemical cleaning.

640

\section{Conclusions}

642 In this study, three processes (i.e., RO alone, FDFO alone and the RO-FDFO hybrid 643 process) in terms of SEC and nutrient concentrations in the final FDFO product water were 644 evaluated and compared. Membrane fouling in FDFO during CSG RO brine treatment was 
645 then investigated and the strategies of controlling membrane fouling were also assessed.

646 The primary findings drawn from this study are summarized as follows:

647

- SEC analysis showed that FDFO alone has the lowest SEC followed by the ROFDFO hybrid process and RO alone.

- Simulation of the final nutrient concentration suggested that the RO-FDFO hybrid system can achieve lower final concentration, higher maximum recovery and lower nutrient loss compared to FDFO process alone.

- From both SEC analysis and final nutrient simulation, it can be drawn that the ROFDFO hybrid process is the most promising process for both CSG RO brine treatment and favorable nutrient supply.

- During CSG RO brine treatment, $\mathrm{KNO}_{3}$ exhibited the highest flux decline than other fertilizers since FS concentration was highly increased due to high RSF.

- CAN showed the most severe membrane scaling caused by reversely transported calcium ions to FS.

- To control membrane fouling in the FDFO process, citric acid cleaning was the most effective chemical agent for chemical cleaning.

\section{Acknowledgements}

This research was supported by a grant (code 16IFIP-B088091-03) from Industrial Facilities \& Infrastructure Research Program funded by Ministry of Land, Infrastructure and Transport of Korean government. 


\section{References}

[1] T.A. Moore, Coalbed methane: A review, International Journal of Coal Geology, 101 (2012) 36-81.

[2] L.D. Nghiem, C. Elters, A. Simon, T. Tatsuya, W. Price, Coal seam gas produced water treatment by ultrafiltration, reverse osmosis and multieffect distillation: A pilot study, Separation and Purification Technology, 146 (2015) 94-100.

[3] L.D. Nghiem, T. Ren, N. Aziz, I. Porter, G. Regmi, Treatment of coal seam gas produced water for beneficial use in Australia: A review of best practices, Desalination and Water Treatment, 32 (2011) 316-323.

[4] G.J. Millar, S.J. Couperthwaite, K. Alyuz, Behaviour of natural zeolites used for the treatment of simulated and actual coal seam gas water, Journal of Environmental Chemical Engineering, 4 (2016) 1918-1928.

[5] H. Zhao, G.F. Vance, M.A. Urynowicz, R.W. Gregory, Integrated treatment process using a natural Wyoming clinoptilolite for remediating produced waters from coalbed natural gas operations, Applied Clay Science, 42 (2009) 379-385.

[6] H. Lee, Y. Jin, S. Hong, Recent transitions in ultrapure water (UPW) technology: Rising role of reverse osmosis (R0), Desalination, 399 (2016) 185-197.

[7] T.H. Chong, S.-L. Loo, W.B. Krantz, Energy-efficient reverse osmosis desalination process, Journal of Membrane Science, 473 (2015) 177-188.

[8] S. Liang, C. Liu, L. Song, Two-Step Optimization of Pressure and Recovery of Reverse Osmosis Desalination Process, Environmental Science \& Technology, 43 (2009) 3272-3277.

[9] Y. Kim, S. Lee, J. Kuk, S. Hong, Surface chemical heterogeneity of polyamide RO membranes: Measurements and implications, Desalination, 367 (2015) 154-160. 
[10] T.Y. Cath, A.E. Childress, M. Elimelech, Forward osmosis: Principles, applications, and recent developments, Journal of Membrane Science, 281 (2006) 70-87.

[11] L. Chekli, S. Phuntsho, J.E. Kim, J. Kim, J.Y. Choi, J.-S. Choi, S. Kim, J.H. Kim, S. Hong, J. Sohn, H.K. Shon, A comprehensive review of hybrid forward osmosis systems: Performance, applications and future prospects, Journal of Membrane Science, 497 (2016) 430-449.

[12] M. Xie, L.D. Nghiem, W.E. Price, M. Elimelech, A Forward OsmosisMembrane Distillation Hybrid Process for Direct Sewer Mining: System Performance and Limitations, Environmental Science \& Technology, 47 (2013) 13486-13493.

[13] T.N. Bitaw, K. Park, D.R. Yang, Optimization on a new hybrid Forward osmosis-Electrodialysis-Reverse osmosis seawater desalination process, Desalination, 398 (2016) 265-281.

[14] S. Phuntsho, S. Hong, M. Elimelech, H.K. Shon, Forward osmosis desalination of brackish groundwater: Meeting water quality requirements for fertigation by integrating nanofiltration, Journal of Membrane Science, 436 (2013) 1-15.

[15] S. Phuntsho, H.K. Shon, S. Hong, S. Lee, S. Vigneswaran, A novel low energy fertilizer driven forward osmosis desalination for direct fertigation: Evaluating the performance of fertilizer draw solutions, Journal of Membrane Science, 375 (2011) 172-181.

[16] S. Phuntsho, H.K. Shon, T. Majeed, I. El Saliby, S. Vigneswaran, J. Kandasamy, S. Hong, S. Lee, Blended Fertilizers as Draw Solutions for Fertilizer-Drawn Forward Osmosis Desalination, Environmental Science \& Technology, 46 (2012) 4567-4575.

[17] Y. Kim, L. Chekli, W.-G. Shim, S. Phuntsho, S. Li, N. Ghaffour, T. Leiknes, H.K. Shon, Selection of suitable fertilizer draw solute for a novel fertilizerdrawn forward osmosis-anaerobic membrane bioreactor hybrid system, Bioresource Technology, 210 (2016) 26-34. 
[18] C. Boo, S. Lee, M. Elimelech, Z. Meng, S. Hong, Colloidal fouling in forward osmosis: Role of reverse salt diffusion, Journal of Membrane Science, 390-391 (2012) 277-284.

[19] S. Lee, Y.C. Kim, Calcium carbonate scaling by reverse draw solute diffusion in a forward osmosis membrane for shale gas wastewater treatment, Journal of Membrane Science, 522 (2017) 257-266.

[20] Y. Kim, S. Li, L. Chekli, Y.C. Woo, C.-H. Wei, S. Phuntsho, N. Ghaffour, T. Leiknes, H.K. Shon, Assessing the removal of organic micro-pollutants from anaerobic membrane bioreactor effluent by fertilizer-drawn forward osmosis, Journal of Membrane Science, 533 (2017) 84-95.

[21] Y. Kim, S. Li, L. Chekli, S. Phuntsho, N. Ghaffour, T. Leiknes, H.K. Shon, Influence of fertilizer draw solution properties on the process performance and microbial community structure in a side-stream anaerobic fertilizer-drawn forward osmosis - ultrafiltration bioreactor, Bioresource Technology.

[22] R. Taddeo, K. Kolppo, R. Lepistö, Sustainable nutrients recovery and recycling by optimizing the chemical addition sequence for struvite precipitation from raw swine slurries, Journal of Environmental Management, 180 (2016) 52-58.

[23] A. Tiraferri, N.Y. Yip, A.P. Straub, S. Romero-Vargas Castrillon, M. Elimelech, A method for the simultaneous determination of transport and structural parameters of forward osmosis membranes, Journal of Membrane Science, 444 (2013) 523-538.

[24] Y.C. Woo, Y. Chen, L.D. Tijing, S. Phuntsho, T. He, J.-S. Choi, S.-H. Kim, H.K. Shon, CF 4 plasma-modified omniphobic electrospun nanofiber membrane for produced water brine treatment by membrane distillation, Journal of Membrane Science, 529 (2017) 234-242.

[25] Y. Kim, S. Lee, H.K. Shon, S. Hong, Organic fouling mechanisms in forward osmosis membrane process under elevated feed and draw solution temperatures, Desalination, 355 (2015) 169-177. 
[26] S. Hong, M. Elimelech, Chemical and physical aspects of natural organic matter (NOM) fouling of nanofiltration membranes, Journal of Membrane Science, 132 (1997) 159-181.

[27] W.S. Ang, S. Lee, M. Elimelech, Chemical and physical aspects of cleaning of organic-fouled reverse osmosis membranes, Journal of Membrane Science, 272 (2006) 198-210.

[28] Y.C. Woo, J.J. Lee, L.D. Tijing, H.K. Shon, M. Yao, H.-S. Kim, Characteristics of membrane fouling by consecutive chemical cleaning in pressurized ultrafiltration as pre-treatment of seawater desalination, Desalination, 369 (2015) 51-61.

[29] Y.C. Woo, Y. Kim, W.-G. Shim, L.D. Tijing, M. Yao, L.D. Nghiem, J.-S. Choi, S.-H. Kim, H.K. Shon, Graphene/PVDF flat-sheet membrane for the treatment of RO brine from coal seam gas produced water by air gap membrane distillation, Journal of Membrane Science, 513 (2016) 74-84.

[30] A. Altaee, G. Zaragoza, H.R. van Tonningen, Comparison between Forward Osmosis-Reverse Osmosis and Reverse Osmosis processes for seawater desalination, Desalination, 336 (2014) 50-57.

[31] S. Phuntsho, S. Hong, M. Elimelech, H.K. Shon, Osmotic equilibrium in the forward osmosis process: Modelling, experiments and implications for process performance, Journal of Membrane Science, 453 (2014) 240252.

[32] J.R. McCutcheon, M. Elimelech, Influence of concentrative and dilutive internal concentration polarization on flux behavior in forward osmosis, Journal of Membrane Science, 284 (2006) 237-247.

[33] N.M. Mazlan, D. Peshev, A.G. Livingston, Energy consumption for desalination - A comparison of forward osmosis with reverse osmosis, and the potential for perfect membranes, Desalination, 377 (2016) 138151.

[34] J.R. McCutcheon, M. Elimelech, Influence of membrane support layer hydrophobicity on water flux in osmotically driven membrane processes, Journal of Membrane Science, 318 (2008) 458-466. 
[35] H.C. Duong, S. Gray, M. Duke, T.Y. Cath, L.D. Nghiem, Scaling control during membrane distillation of coal seam gas reverse osmosis brine, Journal of Membrane Science, 493 (2015) 673-682.

[36] S. Lee, C. Boo, M. Elimelech, S. Hong, Comparison of fouling behavior in forward osmosis (FO) and reverse osmosis (RO), Journal of Membrane Science, 365 (2010) 34-39.

[37] Z. Li, R. Valladares Linares, S. Bucs, C. Aubry, N. Ghaffour, J.S. Vrouwenvelder, G. Amy, Calcium carbonate scaling in seawater desalination by ammonia-carbon dioxide forward osmosis: Mechanism and implications, Journal of Membrane Science, 481 (2015) 36-43.

[38] C. Kim, S. Lee, H.K. Shon, M. Elimelech, S. Hong, Boron transport in forward osmosis: Measurements, mechanisms, and comparison with reverse osmosis, Journal of Membrane Science, 419-420 (2012) 42-48.

[39] E. Filloux, J. Wang, M. Pidou, W. Gernjak, Z. Yuan, Biofouling and scaling control of reverse osmosis membrane using one-step cleaningpotential of acidified nitrite solution as an agent, Journal of Membrane Science, 495 (2015) 276-283.

[40] Y. Zhao, L. Jia, K. Liu, P. Gao, H. Ge, L. Fu, Inhibition of calcium sulfate scale by poly (citric acid), Desalination, 392 (2016) 1-7.

[41] Y. Kim, M. Elimelech, H.K. Shon, S. Hong, Combined organic and colloidal fouling in forward osmosis: Fouling reversibility and the role of applied pressure, Journal of Membrane Science, 460 (2014) 206-212. 